\title{
Pengaruh Struktur Modal, Ukuran Perusahaan, Likuiditas, Pertumbuhan Laba Dan Profitabilitas Terhadap Kualitas Laba (Pada Sektor Aneka Industri yang terdaftar di Bursa Efek Indonesia periode 2015-2019)
}

\author{
Yulia Nurochmah ${ }^{1}$ \\ Universitas Muhammadiyah Tangerang ${ }^{1}$ \\ yuliaanrh08@gmail.com
}

\begin{abstract}
Abstrak: Penelitian ini bertujuan untuk menguji pengaruh struktur modal, ukuran perusahaan, likuiditas petumbuhan laba, profitabilitas terhadap kualitas laba. Populasi penelitian ini adalah seluruh perusahaan manufaktur yang terdaftar di Bursa Efek Indonesia (BEI) mulai tahun 2015 - 2019. Pengambilan sampel dilakukan dengan menggunakan metode purposive sampling yaitu pemilihan sampel dengan kriteria tertentu, sebanyak 51 perusahaan pada sector Aneka Industri. Hasil penelitian ini menunjukkan adanya pengaruh antara struktur modal, likuiditas, ukuran perusahaan, pertumbuhan laba, profitabilitas terhadap kualitas laba.
\end{abstract}

Kata Kunci: Struktur Modal, Likuiditas, Ukuran Perusahaan, Pertumbuhan Laba, Profitabilitas, Kualitas Laba.

Laporan keuangan merupakan proses akhir dari proses akuntansi yang mempunyai peran penting bagi bagi pengukuran dan penilaian kinerja sebuah perusahaan. kualitas laba menjadi pusat perhatian para pengguna laporan keuangan yaitu investor, kreditor, pembuat kebijakan akuntansi dan pemerintah. Pentingnya informasi laba bagi para peng- gunanya menjadikan tiap perusahaan berlomba- lomba meningkatkan labanya. Namun, bagi pihak tertentu ada yang melakukan cara tidaksehat guna mencapai tujuan individunya terhadap informasi laba perusahaan. Hal ini yang menjadikan praktek manipulasi laba. Kualitas laba adalah laba yang secara benar dan akurat menggambarkan profitabilitas operasional perusahaan Sutopo (2009). Rendahnya kualitas laba akan dapat membuat kesalahan pembuatan keputusan para pemakainya seperti investor dan kreditor, sehingga nilai perusahaan akan berkurang (Siallagan dan Machfoedz, 2006). Kasus Toshiba yang mengejutkan seluruh dunia, diketahuilah bahwa Toshiba telah kesulitan mencapai target keuntungan dan menyatakan mengalami kerugian. Krisis tersebut akhirnya Toshiba melakukan suatu kebohongan melalui accounting fraudatau menghasilkan laba yang tidak sesuai dengan realita. Adanya kasus-kasus manipulasi laporan keuangan yang terjadi mengindikasikan bahwa manajemen masih belum menyajikan informasi laba yang sebenarnya kepada principal.

Diduga melakukan manipulasi laporan keuangan dengan membesar-besarkan laba operasional Toshiba sebesar $¥ 151,8$ miliar atau sekitar US\$ 1,22 miliar (Sumber: Liputan6.com, 22 Juli 2015). Dengan adanya praktik rekayasa laba yang dilakukan oleh manajemen akan mengakibatkan kualitas laba yang dilaporkan menjadi rendah, sehingga 
membuat kepercayaan investor terhadap laporan keuangan yang dilaporkan semakin menurun. Rekayasa laba terjadi karena keleluasaan manajemen dalam menentukan metode akuntansi dan kebijakan yang diambilnya. Kualitas laba perusahaan dapat diartikan sebagai kemampuan perusahaan dalam melaporkan laba perusahaan yang menunjukkan laba perusahaan yang sebenarnya, dengan sebaik mungkin melaporkan laba yang akan digunakan untuk memprediksi laba masa depan perusahaan.

Dalam penelitian ini peneliti mereplikasi dari penelitian sebelumnya, sebagaimana yang telah dijelaskan sebelumnya, bagi investor yang akan melakukan investasi ada baiknya memperhatikan besarnya jumlah aset dan hutang yang dimiliki perusahaan.Selain itu variable ukuran perusahaan dan struktur modal, pertumbuhan laba dan profitabilitas juga berpengaruh terhadap kualitas laba.

Batasan Masalah dalam penelitian ini adalah :Menggunakan varibel Dependen Yaitu “ Kualitas Laba”Menggunakan Variabel Independen “ Struktur Modal, Ukuran perusahaan, Likuditas, Pertumbuhan laba dan Profitabilitas.Menggunakan Objek penelitian yaitu pada perusahaan Sektor Aneka Industri yang terdaftar di BEI periode 2017-2018.

Rumusan masalah penelitian ini adalah Bagaimana pengaruh struktur modal, pertumbuhan laba, ukuran perusahaan, dan likuiditas terhadap kualitas laba? Apakah struktur modal berpengaruh terhadap kualitas laba? Apakah pertumbuhan laba berpengaruh terhadap kualitas laba? Apakah ukuran perusahaan berpengaruh terhadap kualitaslaba? Apakah likuiditas berpengaruh terhadap kualitas laba? Adapun tujuan penelitian sebagai berikut : Untuk membuktikan secara empiris struktur modal terhadap kualitas laba, untuk membuktikan secara empiris likuiditas berpengaruh terhadap kualitas laba, untuk membuktikan secara empirisukuran perusahaan terhadap kualitas laba, untuk membuktikan secara empiris Pertumbuhan Laba berpengaruh terhadap kualitas laba, untuk membuktikan secara empiris Proftitabilitas berpengaruh terhadap kualitas laba.

\section{METODE}

Dalam penelitian ini mengunakan jenis data dan analisis yang digunakan dalam penelitian termasuk dalam penelitian kuantitatif karena mengacu pada perhitungan data yang berupa data, sampel dalam penelitian ini adalah perusahaan industri dasar yang terdaftar di Bursa Efek Indonesia (BEI). Pengambilan sampel dalam penelitian ini mengunakan metode purposive sampling yaitu teknik penentuan sampel dengan pertimbangan tertentu ( Sugiyono, 2017 : 67), analisis data yang digunakan adalah analisis Statistik descriptive dan Regresi data panel. 


\section{PROSIDING SEMINAR NASIONAL EKONOMI DAN BISNIS 2021 UNIVERSITAS MUHAMMADIYAH JEMBER}

\begin{tabular}{|l|c|c|c|c|c|c|} 
& $\mathrm{KL}$ & $\mathrm{SM}$ & UP & LIKUID & PROFIT & PL \\
\hline Mean & $\mathrm{KL}$ & $\mathrm{SM}$ & UP & LIKUID & PROFIT & PL \\
\hline Median & 2.084606 & 0.848406 & 28.22358 & 2.107408 & 0.400858 & -0.918676 \\
\hline Maximum & 0.911050 & 0.656500 & 28.06145 & 1.742150 & 0.051750 & 0.101800 \\
\hline Minimum & 26.76250 & 2.693900 & 33.49450 & 7.680700 & 27.15800 & 1.000000 \\
\hline Std. Dev. & -14.89390 & 0.101900 & 20.57610 & 0.003100 & 0.000200 & -65.09690 \\
\hline Skewness & 4.836944 & 0.667329 & 1.826116 & 1.353134 & 3.029936 & 7.358081 \\
\hline Kurtosis & 1.976619 & 1.384148 & 0.411441 & 1.898579 & 8.770984 & -8.463674 \\
\hline & 13.09238 & 3.885348 & 8.127262 & 7.024926 & 77.95825 & 74.20391 \\
\hline Jarque-Bera & 391.6138 & 28.15769 & 89.88649 & 102.0615 & 19754.86 & 17855.11 \\
\hline Probability & 0.000000 & 0.000001 & 0.000000 & 0.000000 & 0.000000 & 0.000000 \\
\hline & & & & & & \\
\hline Sum & 166.7685 & 67.87250 & 2257.887 & 168.5926 & 32.06860 & -73.49410 \\
\hline Sum Sq. Dev. & 1848.286 & 35.18094 & 263.4412 & 144.6467 & 725.2603 & 4277.167 \\
\hline & & & & & & \\
\hline Observations & 80 & 80 & 80 & 80 & 80 & 80 \\
\hline
\end{tabular}

Gambar 1 :Analisis Statistik Deskriptif

Dependent Variable: $\mathrm{KL}$

Method: Panel Least Squares

Date: 07/09/20 Time: 13:29

Sample: 20152019

Periods included: 5

Cross-sections included: 16

Total panel (balanced) observations: 80

\begin{tabular}{crlrr}
\hline \hline \multicolumn{1}{c}{ Variable } & Coefficient & Std. Error & t-Statistic & Prob. \\
\hline \hline C & 11.29344 & 8.349390 & 1.352607 & 0.1803 \\
SM & -0.131673 & 0.807570 & -0.163048 & 0.8709 \\
UP & -0.343600 & 0.285084 & -1.205259 & 0.2319 \\
PROID & 0.150535 & 0.400006 & 0.376331 & 0.7077 \\
PL & -0.155289 & 0.171243 & -0.906836 & 0.3674 \\
& -0.376090 & 0.062066 & -6.059513 & 0.0000 \\
\hline \hline R-squared & 0.343533 & Mean dependent var & 2.084606 \\
Adjusted R-squared & 0.299177 & S.D. dependent var & 4.836944 \\
S.E. of regression & 4.049255 & Akaike info criterion & 5.706981 \\
Sum squared resid & 1213.338 & Schwarz criterion & 5.885633 \\
Log likelihood & -222.2792 & Hannan-Quinn criter. & 5.778608 \\
F-statistic & 7.744935 & Durbin-Watson stat & 1.742465 \\
Prob(F-statistic) & 0.000007 & & & \\
\hline \hline
\end{tabular}

Gambar 2 : Hasil Uji CEM

Dependent Variable: KL

Method: Panel Least Square

(2:41

Sample: 20152019

Cross-sections included: 16

Total panel (balanced) observations: 80

\begin{tabular}{crrrr}
\hline \hline Variable & Coefficient & Std. Error & t-Statistic & Prob. \\
\hline \hline C & 84.92198 & 55.12590 & 1.540510 & 0.1288 \\
SM & -2.090651 & 2.427957 & -0.861074 & 0.3927 \\
UI & -2.854899 & 1.923759 & -1.484021 & 0.1431 \\
PROFI & -0.256420 & 0.515349 & -0.497565 & 0.6206 \\
PL & -0.709327 & 0.509865 & -1.391205 & 0.1694 \\
\multicolumn{5}{c}{} \\
\hline \hline \multicolumn{5}{c}{ Effects Specification } \\
\hline \hline Cross-section fixed (dummy variables) \\
\hline \hline R-squared & 0.593359 & Mean dependent var & 2.084606 \\
Adjusted R-squared & 0.455514 & S.D. dependent var & 4.836944 \\
S.E. of regression & 3.569146 & Akaike info criterion & 5.603041 \\
Sum squared resid & 751.5896 & Schwarz criterion & 6.228323 \\
Log likelihood & -203.1216 & Hannan-Quinn criter. & 5.853734 \\
F-statistic & 4.304549 & Durbin-Watson stat & 2.798781 \\
Prob(F-statistic) & 0.000006 & & \\
\hline \hline
\end{tabular}

Gambar 3 : Hasil Uji FEM 


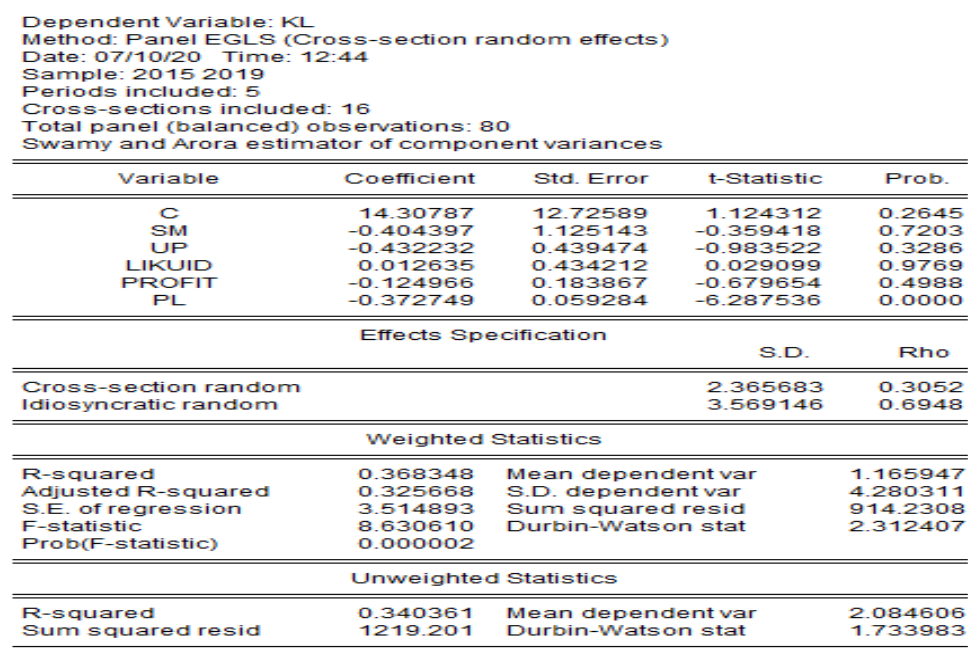

Gambar 4 : Hasil Uji REM

Redundant Fixed Effects Tests

Equation: EQ02

Test cross-section fixed effects

\begin{tabular}{lrrr}
\hline \hline Effects Test & Statistic & d.f. & Prob. \\
\hline \hline Cross-section F & 2.416494 & $(15,59)$ & 0.0083 \\
Cross-section Chi-square & 38.315224 & 15 & 0.0008 \\
\hline \hline
\end{tabular}

Gambar 5 : Hasil Perhitungan Uji Chow

Berdasarkan hasil perhitungan diatas nilai probabiliitas Cross -Section $\mathrm{F}$ dan Cross-section Chi-square sebesar 0.0083 dan $0.0008<(0,05)$ maka dapat disimpulkan bahwa FEM (Fixed Effect Model) lebih layak dibandingkan CEM (Common Effect Model)

Correlated Random Effects - Hausman Test

Equation: EQ02

Test cross-section random effects

\begin{tabular}{lrrr}
\hline \hline Test Summary & Chi-Sq. Statistic & Chi-Sq. d.f. & Prob. \\
\hline \hline Cross-section random & 2.767386 & 5 & 0.7358 \\
\hline \hline
\end{tabular}

Gambar 6 : Hasil Perhitungan Uji Hausman

Berdasarkan hasil perhitungan diatas nilai probabiliitas Cross -Section Random sebesar 0.7358 > $(0,05)$ maka dapat disimpulkan bahwa REM 
(Random Effect Model) lebih layak dibandingkan FEM (Fixed Effect Model)

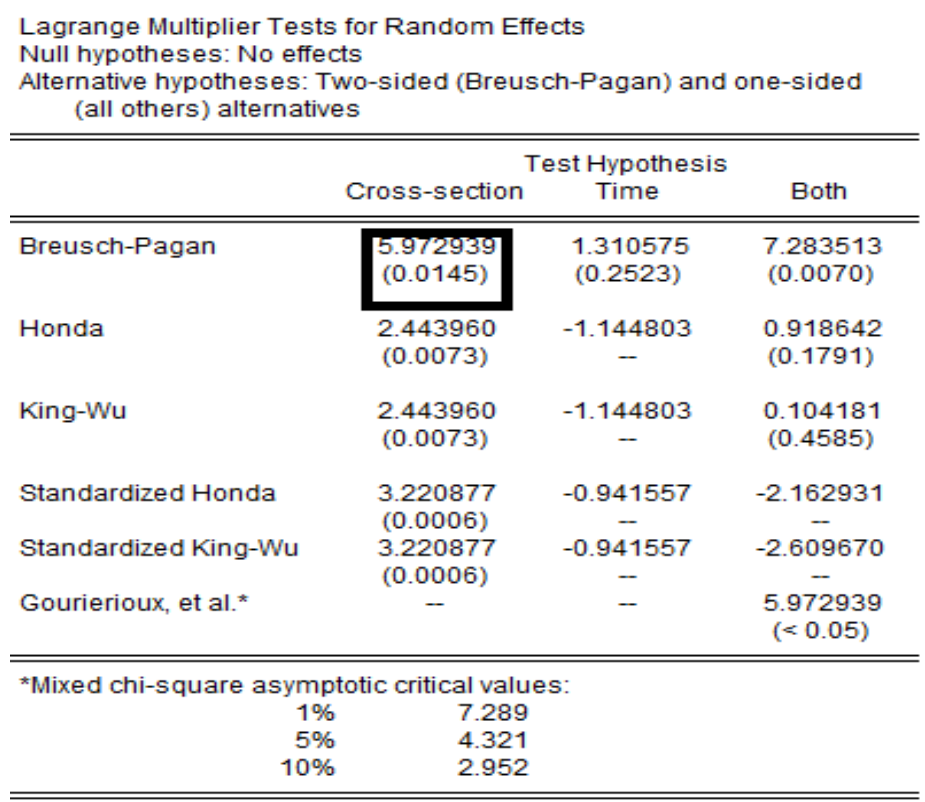

Gambar 7 : Hasil Perhitungan Uji Multiplier

Berdasarkan hasil perhitungan diatas nilai probabilitas Cross-section Breusch Pagan < 0,05 yaitu sebesar 0.0145 maka dapat disimpulkan bahwa REM (Random Effect Model) Lebih layak dibandingkan CEM (Common Effect Model)

\section{Tabel 1. Hasil kesimpulan Uji}

\begin{tabular}{llll}
\hline No & Metode & Pengujian & Hasil \\
\hline 1 & Uji Chow & CEM VS FEM & FEM \\
2 & Uji Hausman & REM VS FEM & REM \\
3 & Uji Lagrange Multiplier & CEM VS REM & REM \\
\hline
\end{tabular}

Berdasarkan hasil pengujian ketiga metode tersebut bahwa Model Regresi Data Panel yang akan digunakan dalam Uji Hipotesis dan persamaan Regresi Data Panel adalan Random Effect Model (REM) 


\begin{tabular}{|c|c|c|c|c|}
\hline \multicolumn{5}{|c|}{$\begin{array}{l}\text { Dependent Variable: KL } \\
\text { Method: Panel Least Squares } \\
\text { Date: } 07 / 10 / 20 \text { Time: } 12: 45 \\
\text { Sample: } 20152019 \\
\text { Periods included: } 5 \\
\text { Cross-sections included: } 16 \\
\text { Total panel (balanced) observations: } 80\end{array}$} \\
\hline Variable & Coefficient & Std. Error & t-Statistic & Prob. \\
\hline $\mathrm{C}$ & 11.29344 & 8.349390 & 1.352607 & 0.1803 \\
\hline SM & -0.131673 & 0.807570 & -0.163048 & 0.8709 \\
\hline UP & -0.343600 & 0.285084 & -1.205259 & 0.2319 \\
\hline LIKUID & 0.150535 & 0.400006 & 0.376331 & 0.7077 \\
\hline PROFIT & -0.155289 & 0.171243 & -0.906836 & 0.3674 \\
\hline PL & -0.376090 & 0.062066 & -6.059513 & 0.0000 \\
\hline R-squared & 0.343533 & \multicolumn{2}{|c|}{ Mean dependent var } & 2.084606 \\
\hline Adjusted R-squared & 0.299177 & \multicolumn{2}{|c|}{ S.D. dependent var } & 4.836944 \\
\hline S.E. of regression & 4.049255 & \multicolumn{2}{|c|}{ Akaike info criterion } & 5.706981 \\
\hline Sum squared resid & 1213.338 & \multicolumn{2}{|c|}{ Schwarz criterion } & 5.885633 \\
\hline & & \multirow{2}{*}{\multicolumn{2}{|c|}{$\begin{array}{l}\text { Hannan-Quinn criter. } \\
\text { Durbin-Watson stat }\end{array}$}} & 5.778608 \\
\hline F-statistic & 7.744935 & & & 1.742465 \\
\hline Prob(F-statistic) & 0.000007 & & & \\
\hline
\end{tabular}

Gambar 8 : Hasil Perhitungan Uji F

Pada data diatas menjelaskan uji $\mathrm{F}$ dari variabel Bahwa Nilai F-Statistic sebesar 7.744935 sementara $F$ Tabel dengan tingkatan $5 \%$, df1 $(\mathrm{k}-1)=$ 5 dan df2 $(n-k)=75$ didapat nilai sebesar 2.34. Dengan Demikian

F-Statistic (7.744935) > F Tabel (2.34)

Nilai Prob(F-Statistic ) $0.0000007<0.05$ maka dapat disimpulkan bahwa Ha diterima, maka dengan demikian dapat simpulkan bahwa Variabel independen dalam penelitian ini yang terdiri dari STRUKTUR MODAL , UKURAN PERUSAHAAN, LIKUIDITAS, PROFITABILITAS, dan PERTUMBUHAN LABA secara bersama sama memiliki pengaruh terhadapa KUALITAS LABA.

Dependent Variable: KL

Method: Panel Least Squares

Date: 07/10/20 Time: $12: 45$

Sample: 20152019

Periods included: 5

Cross-sections included: 16

Total panel (balanced) observations: 80

\begin{tabular}{|c|c|c|c|c|}
\hline Variable & Coefficient & Std. Error & t-Statistic & Prob. \\
\hline $\mathrm{C}$ & 11.29344 & 8.349390 & 1.352607 & 0.1803 \\
\hline $\mathrm{SM}$ & -0.131673 & 0.807570 & -0.163048 & 0.8709 \\
\hline UP & -0.343600 & 0.285084 & -1.205259 & 0.2319 \\
\hline LIKUID & 0.150535 & 0.400006 & 0.376331 & 0.7077 \\
\hline PROFIT & -0.155289 & 0.171243 & -0.906836 & 0.3674 \\
\hline PL & -0.376090 & 0.062066 & -6.059513 & 0.0000 \\
\hline & \multicolumn{3}{|l|}{ عمدعحدمـمـ } & 2.084606 \\
\hline djusted R-squared & 0.299177 & \multirow{2}{*}{\multicolumn{2}{|c|}{$\begin{array}{l}\text { S.D. dependent var } \\
\text { Akaike info criterion }\end{array}$}} & 4.836944 \\
\hline E of ranarosaion & 4040255 & & & 5.706981 \\
\hline Sum squared resid & 1213.338 & \multicolumn{2}{|c|}{ Schwarz criterion } & 5.885633 \\
\hline Log likelihood & -222.2792 & \multirow{2}{*}{\multicolumn{2}{|c|}{$\begin{array}{l}\text { Hannan-Quinn criter. } \\
\text { Durbin-Watson stat }\end{array}$}} & 5.778608 \\
\hline F-statistic & 7.744935 & & & 1.742465 \\
\hline Prob(F-statistic) & 0.000007 & & & \\
\hline
\end{tabular}

Gambar 9 : Hasil Perhitungan koefisien Determinasi 


\begin{tabular}{|c|c|c|c|c|}
\hline \multicolumn{5}{|c|}{$\begin{array}{l}\text { Dependent Variable: KL } \\
\text { Method: Panel EGLS (Cross-section random effects) } \\
\text { Date: } 07 / 10 / 20 \text { Time: } 12: 44 \\
\text { Sample: } 20152019 \\
\text { Periods included: } 5 \\
\text { Cross-sections included: } 16 \\
\text { Total panel (balanced) observations: } 80 \\
\text { Swamy and Arora estimator of component variances } \\
\end{array}$} \\
\hline Variable & Coefficient & Std. Error & t-Statistic & Prob. \\
\hline C & 14.30787 & 12.72589 & 1.124312 & 0.2645 \\
\hline SM & -0.404397 & 1.125143 & -0.359418 & 0.7203 \\
\hline UP & -0.432232 & 0.439474 & -0.983522 & 0.3286 \\
\hline LIKUID & 0.012635 & 0.434212 & 0.029099 & 0.9769 \\
\hline PROFIT & -0.124966 & 0.183867 & -0.679654 & 0.4988 \\
\hline PL & -0.372749 & 0.059284 & -6.287536 & 0.0000 \\
\hline \multicolumn{5}{|c|}{ Effects Specification } \\
\hline & & & S.D. & Rho \\
\hline Cross-section random & & & 2.365683 & 0.3052 \\
\hline Idiosyncratic random & & & 3.569146 & 0.6948 \\
\hline \multicolumn{5}{|c|}{ Weighted Statistics } \\
\hline R-squared & 0.368348 & \multirow{5}{*}{\multicolumn{2}{|c|}{$\begin{array}{l}\text { Mean dependent var } \\
\text { S.D. dependent var } \\
\text { Sum squared resid } \\
\text { Durbin-Watson stat }\end{array}$}} & 1.165947 \\
\hline Adjusted R-squared & 0.325668 & & & 4.280311 \\
\hline S.E. of regression & 3.514893 & & & 914.2308 \\
\hline F-statistic & 8.630610 & & & 2.312407 \\
\hline Prob(F-statistic) & 0.000002 & & & \\
\hline \multicolumn{5}{|c|}{ Unweighted Statistics } \\
\hline R-squared & 0.340361 & \multirow{2}{*}{\multicolumn{2}{|c|}{$\begin{array}{l}\text { Mean dependent var } \\
\text { Durbin-Watson stat }\end{array}$}} & 2.084606 \\
\hline Sum squared resid & 1219.201 & & & 1.733983 \\
\hline
\end{tabular}

Gambar 10 : Hasil perhitungan Uji t

Dalam teori sinyal, informasi dalam penyajian laporan keuangan sangat dibutuhkan bagi para pengguna, dalam fenomena penelitian ini untuk mengetahui bagaimana kinerja laba sebagai evaluasi dari pemegang saham ke manajemen dalam melihat kualitas laba. Apabila menurun maka yang dilakukan oleh manajemen memberikan sinyal negatif, dan sebaliknya apabila yang dilakukan manajemen membuat kualitas laba meningkat maka hal tersebut memberikan sinyal positif kepada para pemegang saham.

1. Variabel Struktur Modal tidak memilki pengaruh terhadap Kuallitas Laba dengan Nilai T-Statistik SM ialah 0,2645.

2. Variabel Ukuran perusahaan tidak memilki pengaruh terhadap Kuallitas Laba dengan Nilai T-Statistik UP ialah 0,7203.

3. Variabel Likuiditas tidak memilki pengaruh terhadap Kuallitas Laba dengan Nilai T-Statistik Likuiditas ialah 0.3286.

4. Variabel Pertumbuhan Laba memilki pengaruh terhadap Kuallitas Laba dengan Nilai T-Statistik 0,0000

5. Variabel Profitasbilitas tidak memilki pengaruh terhadap Kuallitas Laba dengan Nilai T-Statistik 0,4988.

\section{KESIMPULAN}

Dari hasil penelitian ini maka dapat diperoleh beberapa kesimpulan yaitu :

a. Variabel Variabel Struktur Modal tidak memilki pengaruh terhadap Kuallitas Laba

b. Variabel Ukuran perusahaan tidak memilki pengaruh terhadap Kuallitas Laba. 
c. Variabel Likuiditas tidak memilki pengaruh terhadap Kuallitas Laba.

d. Variabel Pertumbuhan Laba memilki pengaruh terhadap Kuallitas Laba.

e. Variabel Profitasbilitas tidak memilki pengaruh terhadap Kuallitas Laba.

\section{DAFTAR PUSTAKA}

https://liputan6.com. diakses 22 Juli 2015

Siallagan, H. and Machfoedz, M.U., 2006. Mekanisme corporate governance, kualitas laba dan nilai perusahaan. Simposium Nasional Akuntansi, 9(61), pp.23-26.

Sugiyono. 2017. Metode Penelitian Kuantitatif, Kualitaif dan R\&D. Bandung: Alfabeta

Yuwono, Sutopo. 2009. Dasar - Dasar Produksi,Yogyakarta: Pustaka Pelajar 